\title{
Effects of flanking regions on HDV cotranscriptional folding kinetics
}

YANLI WANG, ZHEN WANG, TAIGANG LIU, SHA GONG, and WENBING ZHANG

Department of Physics, Wuhan University, Wuhan, Hubei 430072, P.R. China

\begin{abstract}
Hepatitis delta virus (HDV) ribozyme performs the self-cleavage activity through folding to a double pseudoknot structure. The folding of functional RNA structures is often coupled with the transcription process. In this work, we developed a new approach for predicting the cotranscriptional folding kinetics of RNA secondary structures with pseudoknots. We theoretically studied the cotranscriptional folding behavior of the 99-nucleotide (nt) HDV sequence, two upstream flanking sequences, and one downstream flanking sequence. During transcription, the 99-nt HDV can effectively avoid the trap intermediates and quickly fold to the cleavage-active state. It is different from its refolding kinetics, which folds into an intermediate trap state. For all the sequences, the ribozyme regions (from 1 to 73 ) all fold to the same structure during transcription. However, the existence of the 30-nt upstream flanking sequence can inhibit the ribozyme region folding into the active native state through forming an alternative helix Alt1 with the segments 70-90. The longer upstream flanking sequence of 54 nt itself forms a stable hairpin structure, which sequesters the formation of the Alt1 helix and leads to rapid formation of the cleavage-active structure. Although the 55-nt downstream flanking sequence could invade the already folded active structure during transcription by forming a more stable helix with the ribozyme region, the slow transition rate could keep the structure in the cleavage-active structure to perform the activity.
\end{abstract}

Keywords: HDV ribozyme; cotranscriptional; folding kinetics; pathway; pseudoknot

\section{INTRODUCTION}

RNA can carry out numerous biological functions, such as translating genetic information into proteins (Skog et al. 2008; Mercer et al. 2009), regulating gene expression (Grundy and Henkin 1998; Batey et al. 2004), and catalyzing biochemical processes (Cheah et al. 2007; Neupane et al. 2011; Li and Breaker 2013; Lin and Thirumalai 2013; Reining et al. 2013; Hoffmann et al. 2014) by forming specific secondary and tertiary structures. RNA pseudoknots are examples of minimal structural motifs in structured RNAs with tertiary interactions. They have been found to play important roles in a wide range of biological functions, from ribosomal frameshifting (Gesteland and Atkins 1996; Kim et al. 1999; Giedroc et al. 2000; Plant et al. 2003; Cornish et al. 2005; Plant and Dinman 2005) to human telomerase RNA (hTR) activity (Comolli et al. 2002; Theimer et al. 2003; Chen and Greider 2005; Marrone et al. 2005). Many ribozymes (Lehnert et al. 1996; Zarrinkar and Williamson 1996; Ferré-D’Amaré et al. 1998; Treiber et al. 1998; Pan and Woodson 1999; Russell et al. 2000; Schultes and Bartel

Corresponding author: wbzhang@whu.edu.cn

Article is online at http://www.rnajournal.org/cgi/doi/10.1261/rna.065961. 118.
2000) form a well-defined 3D enzymatic shape with pseudoknots. The HDV ribozyme is a small, single-stranded RNA satellite of hepatitis $\mathrm{B}$ virus (HBV), which can enhance the virulence of HBV infections. HDV replicates by a double rolling-circle model and the nascent RNA is processed into monomers by self-cleavage of the genomic or antigenomic ribozyme (Lai 1995; Taylor et al. 1996; Taylor 2006; Kapral et al. 2014). Pseudoknot structure is also important for HDV ribozyme function (Perrotta and Been 1990, 1991; Wadkins et al. 1999). A detailed understanding of the folding pathway of this ribozyme may provide insight into replication of HDV and help identify targets for therapeutics.

The folding of functional RNA structures is often coupled with the transcription process (Sharma et al. 2010; Ameur et al. 2011; Tilgner et al. 2012; Brugiolo et al. 2013; Hamperl and Cimprich 2014). For instance, the functional native structure of the tetrahymena group I intron may form within the timescale of transcription, which is much faster than the

(C) 2018 Wang et al. This article is distributed exclusively by the RNA Society for the first 12 months after the full-issue publication date (see http:// rnajournal.cshlp.org/site/misc/terms.xhtml). After 12 months, it is available under a Creative Commons License (Attribution-NonCommercial 4.0 International), as described at http://creativecommons.org/licenses/by-nc/4.0/. 
refolding of the complete chain in vitro (Brehm and Cech 1983; Wu and Tinoco 1998; Treiber and Williamson 2001; Heilman-Miller and Woodson 2003). It has been proposed that natural RNAs can effectively avoid the formation of misfolded structures during the cotranscriptional folding process (Kramer and Mills 1981; Treiber and Williamson 1999; Wong et al. 2007), but the mechanism is still not completely clear. In vivo, during the transcription elongation, because the upstream has already been folded, this will further influence the folding pathways of the downstream section. Recently, a few experiments have studied the self-cleavage activity of the HDV ribozyme during transcription (Chadalavada et al. 2000, 2002, 2007; Diegelman-Parente and Bevilacqua 2002). A clear and detailed understanding of the kinetic process of RNA folding including the folding pathways during transcription is crucial for uncovering the mechanism of RNA functions.

Many theoretical methods have been used to study the RNA folding kinetics. A few works have attempted to improve the energy parameters of pseudoknots (Cao and Chen 2005, Zhang et al. 2008). Molecular dynamic and Monte Carlo (MC) simulation approaches have been used to study the transition states, kinetic intermediates, and folding trajectories for a few specific sequences (Gultyaev 1991; Flamm et al. 2000; Isambert and Siggia 2000; Sorin et al. 2002; Krasovska et al. 2005; Yingling and Shapiro 2005; Danilova et al. 2006; Lin and Thirumalai 2008; Veeraraghavan et al. 2010), but the methods are limited to short timescales as a result of the restrictions of the computational efficiency and incomplete conformational sampling. Though coarsegrained models have already been developed to study RNA folding (Cho et al. 2009; Denesyuk and Thirumalai 2011; Shi et al. 2011), they are still limited to the simple H-pseudoknot folding without long life intermediate states. Based on coarse-grained kinetic moves, which can effectively reduce the number of conformations, several computational methods have been developed (Mironov et al. 1985; Geis et al. 2008; Tang et al. 2008; Hofacker et al. 2010); however, these simplified kinetic moves would miss the important folding pathways for some sequences/structures. Cao and Chen (Cao and Chen 2006) investigated RNA pseudoknot folding and unfolding kinetics with a combined master equation and kinetic cluster approach, but the method is also limited to short chains with small conformational preequilibrated macro-states.

In this study, we combine the methods of predicting the folding kinetics of the pseudoknots (Chen et al. 2014), the cotranscription folding kinetics theory (Zhao et al. 2011; Gong et al. 2015a) of the secondary structures, and the transition node approximation method (Gong et al. 2015b) for long RNAs to establish a systematic method to predict the cotranscription folding kinetics of a long RNA chain with pseudoknots. Then we further studied how the flanking regions affect the HDV self-cleavage function during transcription.

\section{RESULTS}

\section{Cotranscriptional folding for 99-nt HDV ribozyme can avoid forming trap intermediates}

To test the validity of the transition node approximation, we first predict the cotranscriptional folding kinetics of the 99-nt sequence (which contains 84-nt ribozyme sequence and 15nt downstream flanking sequence) for the HDV ribozyme at a transcription rate of $15 \mathrm{nt} / \mathrm{sec}$ using the original theory (Zhao et al. 2011) and the approximation method. Applying the transition node approximation reduces the number of conformations from 1884 to 142 at the end of transcription. As shown in Figure 1, the results show that from step 1 to step 99, the population kinetics of the main states are almost identical for the two methods. This indicates that the approximation effectively reduces the number of conformations and can reliably predict the cotranscriptional folding kinetics of longer nascent RNA chains. Hence, we would use the new method to study the cotranscriptional folding kinetics of HDV with different lengths.

For the 99-nt sequence, as the chain grows, the nascent RNA chain folds to the native state $\mathrm{C} 8$ through a series of discrete intermediate states (C0-C8) (Fig. 1): (i) When the first 13 nucleotides (nt) are released by the RNAP, the hairpin structure $\mathrm{C} 1$ is formed. (ii) At step 29, structure C1 quickly converts to structure C2 by adding a new hairpin. (iii) From step 37, most of the structure C2 quickly transits to structure C3, and a small fraction of structure $\mathrm{C} 2$ converts to structure C4. Besides, structure C3 can slowly transit to structure C4. (iv) At step 63, structure C3 almost all converts to structure C5, which only stays several steps. (v) From step 64, a part of helix P4 begins to form, so the structures $\mathrm{C} 5$ and $\mathrm{C} 4$ quickly convert to structures $\mathrm{C} 6$ and $\mathrm{C} 7$ by adding helix P4, respectively. At the same time, structure C6 can slowly transit to structure C7. (vi) From the 81st step, structure C6 quickly converts to native structure $\mathrm{C} 8$, and a small fraction transits to $\mathrm{C7}$. At the end of the transcription, the inactive structure $\mathrm{C} 7$ only occupies $\sim 10.18 \%$ and the active structure C8 occupies $\sim 78.37 \%$.

The cotranscriptional folding of the wild 99-nt HDV ribozyme can effectively avoid the meta-stable intermediate C7, which occupies $\sim 50 \%$ of the population and lasts $\sim 30 \mathrm{~min}$ and then transits to the native state in the refolding process (Chadalavada et al. 2000, 2002). The cotranscriptional folding also shows bifurcation folding behavior from step 34, one pathway as C2-C3-C5-C6-C8 would directly fold to the native state, another pathway folds to the intermediate state along C2-C4-C7. Although structure C2 begins to directly convert to structures $\mathrm{C} 3$ and $\mathrm{C} 4$ at the same time from step 34, the transition rate from $\mathrm{C} 2$ to $\mathrm{C} 3$ $\mathrm{k}_{\mathrm{C} 2 \rightarrow \mathrm{C} 3} \approx 1.48 \times 10^{2} \mathrm{sec}^{-1}$ is larger than that from C2 to $\mathrm{C} 4, \mathrm{k}_{\mathrm{C} 2 \rightarrow \mathrm{C} 4} \approx 3.09 \times 10^{0} \mathrm{sec}^{-1}$, which is not a zipping process due to a bulge loop. Even though the structure $\mathrm{C} 4$ $(\Delta \mathrm{G}=-21.19 \mathrm{kcal} / \mathrm{mol})$ is more stable than structure $\mathrm{C} 3$ $(\Delta \mathrm{G}=-19.31 \mathrm{kcal} / \mathrm{mol})$, when the sequence grows to 
A

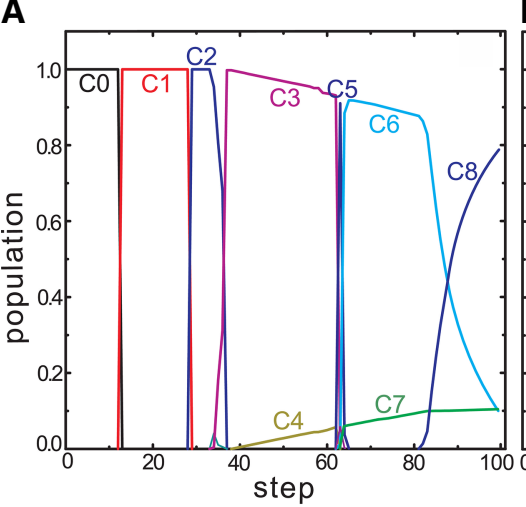

B

C

D
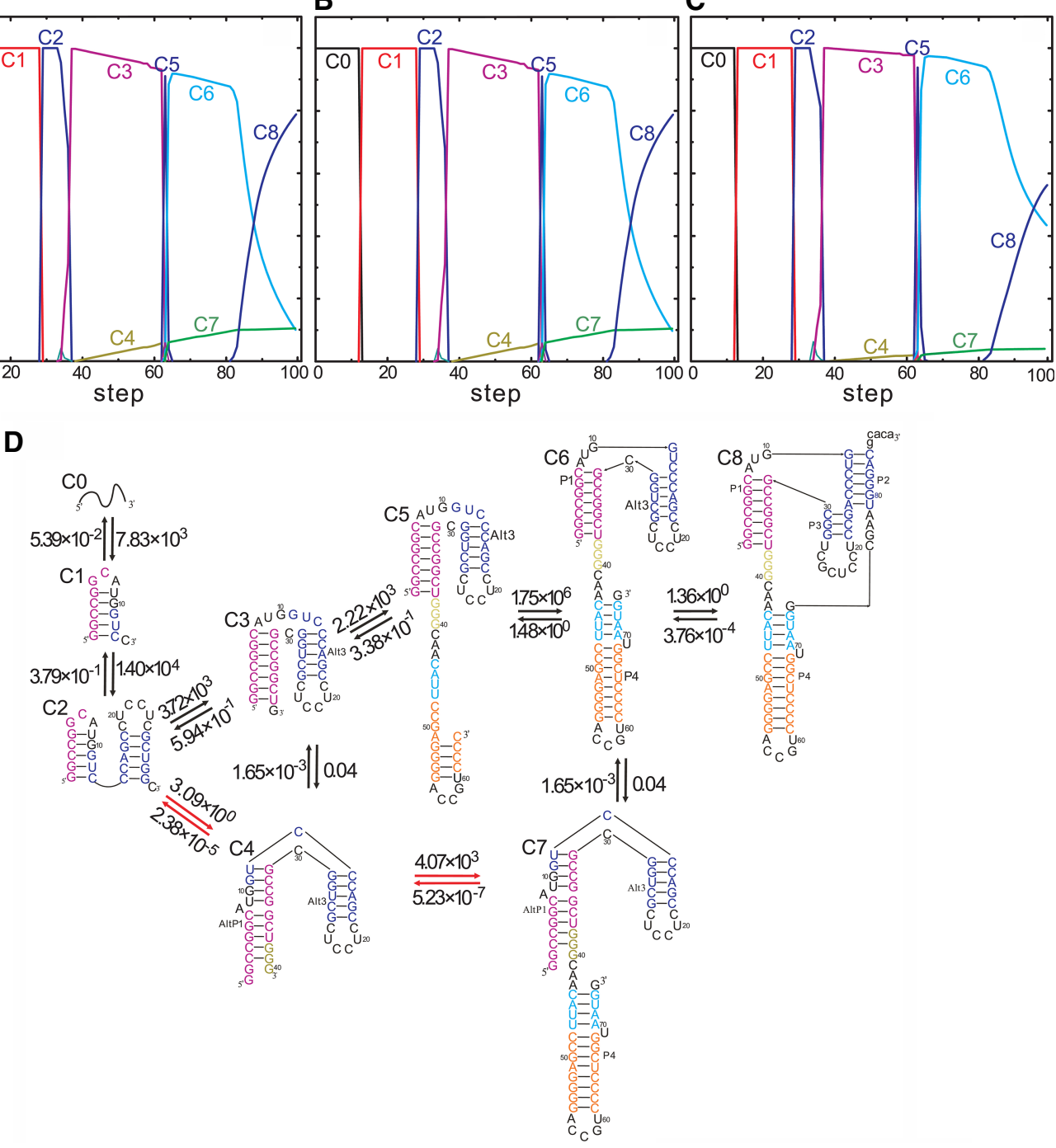

FIGURE 1. The population kinetics of main states (C0-C8) formed during the transcription $(A)$ at a transcription rate of $15 \mathrm{nt} / \mathrm{sec}$ with the original theory, $(B)$ and $(C)$ with the node approximation method at a transcription rate of 15 and $40 \mathrm{nt} / \mathrm{sec}$, respectively. $(D)$ The folded structures and pathways during transcription. Upper case letters denote the ribozyme regions; lower case letters denote the flanking regions. The transition rates (unit $\mathrm{sec}^{-1}$ ) along the arrow are labeled.

step 39, most of the population structure C2 fluxes to structure $\mathrm{C} 3$ instead of $\mathrm{C} 4$, which indicates that the cotranscriptional folding behavior is a nonequilibrium folding kinetics. However, although the structure $\mathrm{C} 3$ could transit to $\mathrm{C} 4$ through a helix exchanging pathway (helix P1 exchange to helix AltP1), according to the steady-state approximation, the rates between the two structures could be obtained through Equation 8 as follows: $k_{\mathrm{C} 3 \rightarrow \mathrm{C} 4} \approx 0.04 \mathrm{sec}^{-1}$, $k_{\mathrm{C} 4 \rightarrow \mathrm{C} 3} \approx 1.65 \times 10^{-3} \mathrm{sec}^{-1}$. Along the two pathways C3$\mathrm{C} 5-\mathrm{C} 6-\mathrm{C} 8$ and $\mathrm{C} 4-\mathrm{C} 7$, the transitions are very fast through adding a new helix at each transition step, so most of the population would transit to the native state C8 from C3, and only a small fraction of the population would transit to the intermediate state C7 from C4. Structure C6 could also transit to structure $\mathrm{C} 7$ along the pathway as the transition from $\mathrm{C} 3$ to $\mathrm{C} 4$ through helix AltP1 exchanging with helix P1 and has the same transition rates. So from step 39 to 81 , at which structure $\mathrm{C} 8$ is more stable than $\mathrm{C} 7$, the population flow from the upper pathway to the lower pathway at the time window $(81-39) / v$ sec could be approximated as $P_{\text {lower }}=p_{3}\left(1-e^{-k_{3 \rightarrow 4} t}\right) \approx 10.06 \%$.

To further explore the effects of the transcription rate on the cotranscriptional folding kinetics, the cotranscriptional folding behavior with transcription rate $40 \mathrm{nt} / \mathrm{sec}$ has been studied. As shown in Figure 1C, the only difference is that the intermediate state C7 has an even lower population. This is because the time window $42 / v$ sec from the upper pathway to the lower pathway is shorter at the transcription rate $40 \mathrm{nt} / \mathrm{sec}$ than that at $15 \mathrm{nt} / \mathrm{sec}$, the population for structure C7 decreases from $10.18 \%$ to $3.93 \%$. Although at step 99 the population of structure C8 $(\sim 78.38 \%)$ decreases to $53.83 \%$, the other population is in structure C6, and would 
A

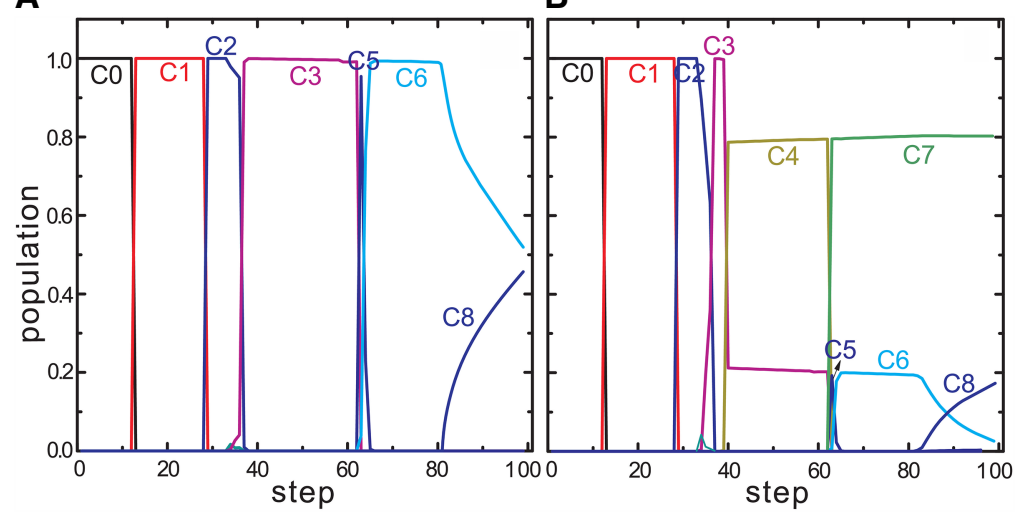

FIGURE 2. The population kinetics of main states $(\mathrm{C} 0-\mathrm{C} 8)$ formed during the transcription $(A)$ at a transcription rate of $200 \mathrm{nt} / \mathrm{sec},(B)$ at a transcription rate of $15 \mathrm{nt} / \mathrm{sec}$ with pausing $(45 \mathrm{sec})$ at step 39.

transit to $\mathrm{C} 8, \sim 0.18 \mathrm{sec}$. The results indicate that accelerating the transcriptional rate can lead to more conformation flux to native structure. As the transcription rate further increases to $200 \mathrm{nt} / \mathrm{sec}$, the lower pathway almost vanishes and at the end of transcription, the intermediate structure only occupies $\sim 1.87 \%$ (see Fig. 2A). Although the structures (C4 and C7) on the slow pathway have the lowest free energy during the transcription until step 81, as the cotranscription folding is a nonequilibrium kinetic process, even at the slowest transcription rate, they could only occupy a small portion of the population, which is far less than its equilibrium population $(\sim 90 \%)$. At a higher transcription rate, there would be less time to get equilibration, so the intermediate state would get less population.

Transcription often pauses at U-rich sites (Gusarov and Nudler 1999; Artsimovitch and Landick 2000). Recently, it was found that pausing at a special site could lead to different folding structures (Helmling et al. 2018). Here, we use the 99-nt HDV ribozyme sequence as a model to test the effects of transcription pausing on the folding. Suppose the pausing time is $45 \mathrm{sec}$ at step 39; the folding results are different from that without pausing (Fig. 2B). At the end of transcription, the inactive intermediate structure C7 occupies $\sim 80 \%$ of the population. Transcription pausing would provide extra time for the system to get equilibration, as the intermediate structures ( $\mathrm{C} 4$ and $\mathrm{C} 7$ ) have the lowest free energy, so more population would go to the intermediate structure.

\section{The 30-nt upstream fragment can lead to HDV ribozyme inactivity by forming an Alt1 helix with the segments 70-90}

To explore how the flanking sequence affects the genomic HDV self-cleavage during transcription, the cotranscription folding kinetics of the 129-nt HDV ribozyme (from -30 to 99 fragment, with a 30-nt upstream) were also studied. As the chain increases, the nascent chain folds into a series of discrete intermediate states and at the end of transcription, the structure S12 occupies $\sim 87.1 \%$ and the structure $S 13$ is $\sim 10.2 \%$. Both of them do not contain the pseudoknot structure (Fig. 3). So the 30-nt upstream sequence leads to the HDV in cleavage-inactive states. The experimental results showed that for this sequence, the reaction was not complete after $24 \mathrm{~h}$ and helix Alt1 was formed (Chadalavada et al. 2000; DiegelmanParente and Bevilacqua 2002). Our results are consistent with the experiments. Although there are little differences among the folded structures before nucleotide 63 is transcribed for the 129and 99-nt sequences, they all fold into the same structures, denoted by $\mathrm{S} 10$ and C6, respectively, when nucleotides 64-81 are transcribed. For the 99-nt sequence, structure C6 would transit to the cleavage active state C8. For the 129-nt sequence, the structure S10 could also transit to the cleavage active state S14 with the same rate as that from $\mathrm{C} 6$ to $\mathrm{C} 8$. But from the nucleotide 82 transcribed, due to the ability of the upstream segment to form an Alt1 helix with nucleotides 79-86, structure S10 could also transit to structure S12 by adding the Alt1 helix. As structure S10 transits to S12 through adding the Alt1 helix, the transition rate from S10 to $S 12 k_{S 10 \rightarrow S 12}=$ $4.13 \times 10^{3} \mathrm{sec}^{-1}$ is much larger than that from S10 to S14. Also, the free energy of $\mathrm{S} 12(\Delta \mathrm{G}=-52.70 \mathrm{kcal} / \mathrm{mol})$ is much lower than that of $S 14(\Delta \mathrm{G}=-43.45 \mathrm{kcal} / \mathrm{mol})$. So, most of the population would transit to the cleavage inactive state $\mathrm{S} 12$.

\section{The 54-nt upstream region can restore HDV ribozyme activity by forming a self-structure $\mathbf{P}(-1)$ helix}

For the 153-nt HDV ribozyme (from -54 to 99, with a 54-nt upstream segment), the nascent chain folds into a series of discrete intermediate states, and at the end of transcription, the active structure X12 occupies $~ 83.1 \%$, while the inactive structure X13 occupies only $5.63 \%$ (Fig. 4 ), which is different from that of the 30-nt upstream flanking sequence but is similar to that of the 99-nt sequence. For the 153-, 129-, and 99-nt sequences, when the nucleotide 73 is released, the ribozyme regions (from nucleotide 1 to nucleotide 73) of the three sequences fold to the same structures denoted as $\mathrm{C} 6, \mathrm{~S} 10$, and $\mathrm{X10}$, respectively. The main difference is that for the 153-nt sequence, structure X10 includes a stable helix $\mathrm{P}(-1)$, which consists of the upstream sequence (from -54 to -17$)$. Because the early formed $\mathrm{P}(-1)$ helix is stable, exchanging this helix with Alt1 is not only thermodynamically unfavorable but also kinetically unfavorable. So the $\mathrm{P}(-1)$ helix can prevent the 30-nt upstream segment from pairing with nucleotides $79-86$ to form an Alt1 helix. Structure 

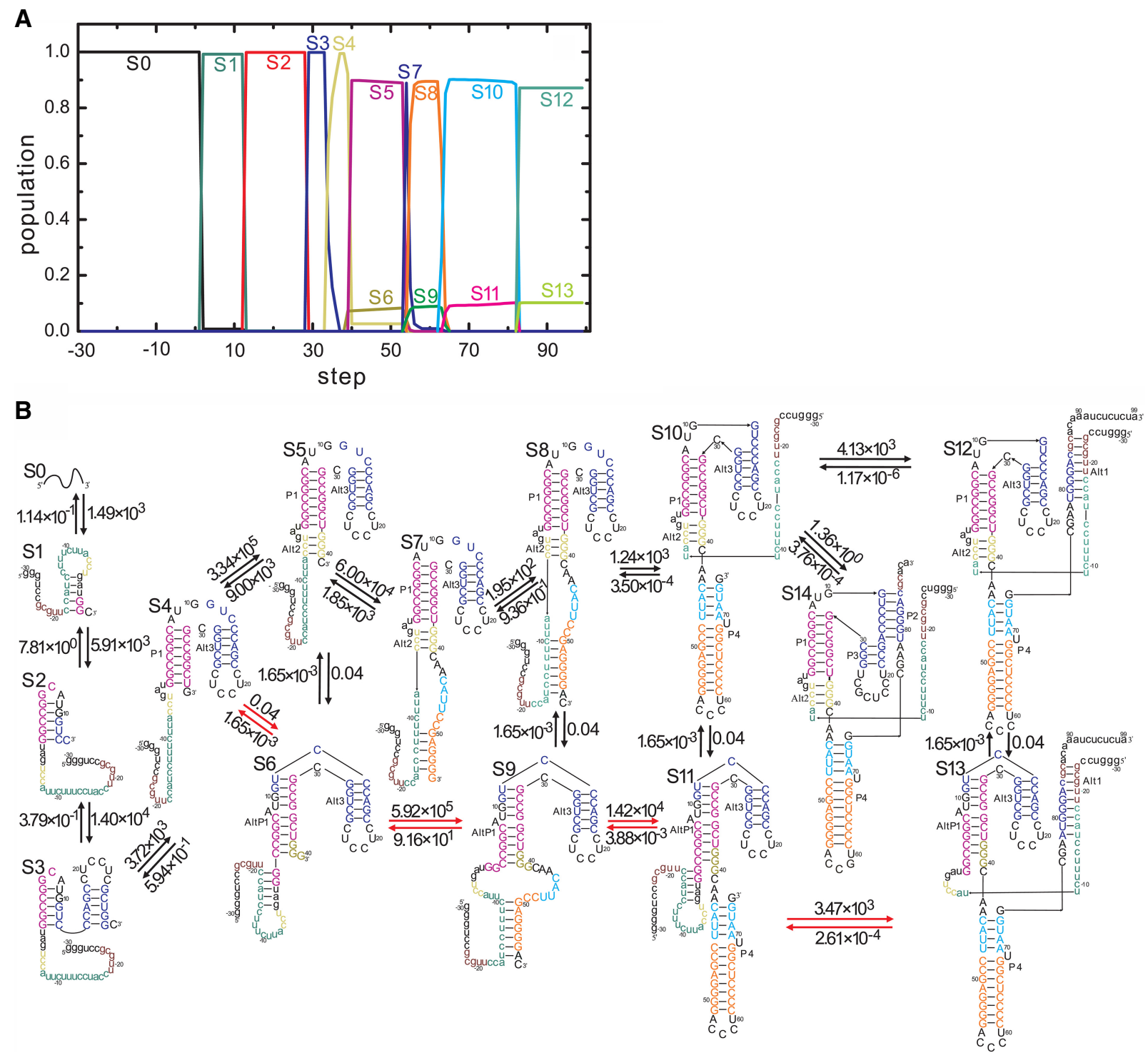

FIGURE 3. $(A)$ The population kinetics of main states (S0-S14) formed during the transcription at a transcription rate of $15 \mathrm{nt} / \mathrm{sec}$ for HDV ribozyme with 30-nt upstream segment. (B) The folded structures and the transition pathways during the transcription. Upper case letters denote the ribozyme regions; lower case letters denote the flanking regions. The transition rates (unit $\mathrm{sec}^{-1}$ ) along the arrow are labeled.

$\mathrm{X} 10$ would transit to the cleavage active state $\mathrm{X} 12$ as the similar ways of the structure C6 transits to structure C8 for the 99-nt sequence. For this sequence, the experiments (Chadalavada et al. 2000; Diegelman-Parente and Bevilacqua 2002) detected that the RNA was nearly completely cleaved during transcription and detected the hairpin $\mathrm{P}(-1)$. Our prediction is in agreement with the experimental results.

\section{The cotranscriptional folding is important for the HDV ribozyme with a 55-nt downstream region to perform cleavage activity}

To further study the effects of the downstream flanking sequence on the cotranscriptional folding kinetics, we studied the cotranscriptional folding kinetics of the 140-nt (85-nt ri- bozyme region and 55-nt downstream fragment) sequence. When nucleotide 110 is released, it folds as the same structures as that of the $99 \mathrm{nt}$, the active structure C8 occupies $\sim 85 \%$ of the population, and the inactive structure $\mathrm{C} 7 \mathrm{occu}-$ pies $\sim 12 \%$ of the population (Fig. 5). When nucleotide 113 is transcribed, the downstream segment would fold to a hairpin AltP5, and then C8 would transit to structure C10 by adding the helix AltP5. If there is further elongation to nucleotide 128 , the downstream segment would fold to a more stable helix P5, and the structure would transit from C10 to C14 through helix exchanging. Meanwhile, a small portion of the population would transit to $\mathrm{C} 12$ from $\mathrm{C} 7$ as that from $\mathrm{C} 8$ to $\mathrm{C} 14$.The self-cleavage structure $\mathrm{C} 14$ occupies $\sim 81.5 \%$, and the inactive structure $\mathrm{C} 13$ occupies $\sim 14.7 \%$. But when the downstream segments 129 to 132 are transcribed, this 


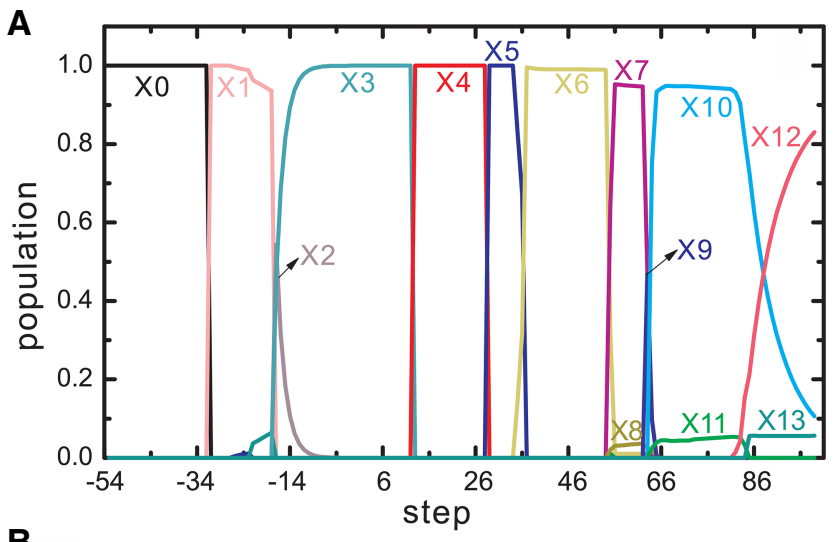

B
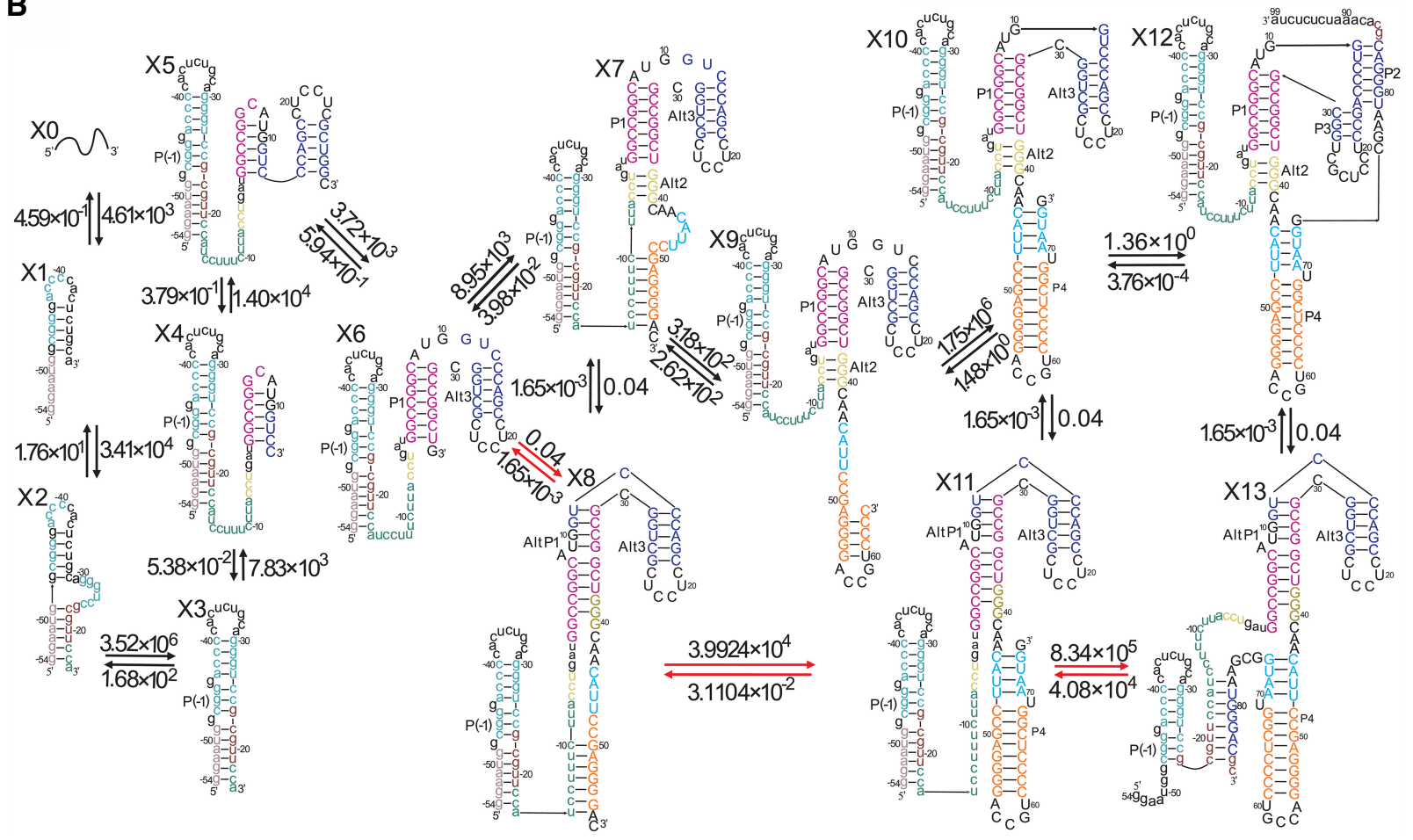

FIGURE 4. (A) The population kinetics of main states (X0-X13) formed during the transcription at a transcription rate of $15 \mathrm{nt} / \mathrm{sec}$ for $153 \mathrm{nt}$. $(B)$ The folded structures and the transition pathways during the transcription. Upper case letters denote the ribozyme regions; lower case letters denote the flanking regions. The pathways, the structure of the states, and the transition rates (unit $\sec ^{-1}$ ) along the arrow are labeled.

segment could form base pairs with the segments 80 to 83 of the ribozyme region, structure C12 would transit to C13. But this helix could not coexist with the P2 helix of active structure C14. Although the free energy of structure $\mathrm{C} 13(\Delta \mathrm{G}=-56.78 \mathrm{kcal} / \mathrm{mol})$ is lower than that of C14 $(\Delta \mathrm{G}=-53.80 \mathrm{kcal} / \mathrm{mol})$, which occupies most of the population before $\mathrm{C} 13$ could be formed due to the cotranscription folding, as the transition rate from $\mathrm{C} 14$ to $\mathrm{C} 13$ $k_{C 14 \rightarrow C 13} \approx 0.04 \mathrm{sec}^{-1}$ is much slower than the self-cleavage rate $k_{c}=40 \mathrm{~min}^{-1}$ (Diegelman-Parente and Bevilacqua 2002), most of the native structure is self-cleaved before the native structure $\mathrm{C} 14$ transits to the alternative structure C13. For this sequence the experimental results showed that the RNA was almost completely cleaved during transcription and inferred the existence of helix P5 (Diegelman-Parente and Bevilacqua 2002; Chadalavada et al. 2007). Our prediction is consistent with the experimental results.

\section{DISCUSSION}

The HDV ribozyme, a human pathogen, has genomic and antigenomic versions of a small ribozyme embedded in its 1.7-kb RNA genome (Lai 1995; Lazinski and Taylor 1995; Karayiannis 1998). By virtue of their roles in rolling-circle viral replication, these small ribozymes have evolved to function cotranscriptionally in the presence of flanking sequence. To study the cotranscriptional folding kinetics, we have extended the newly developed RNA cotranscription folding 
A

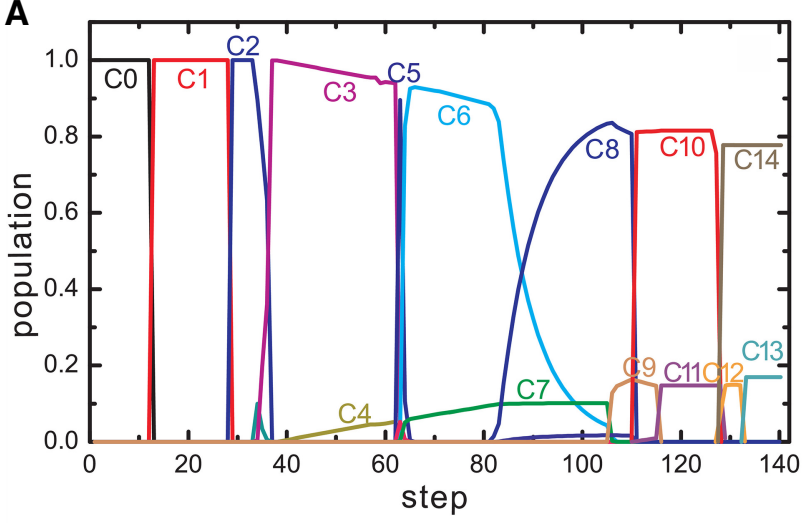

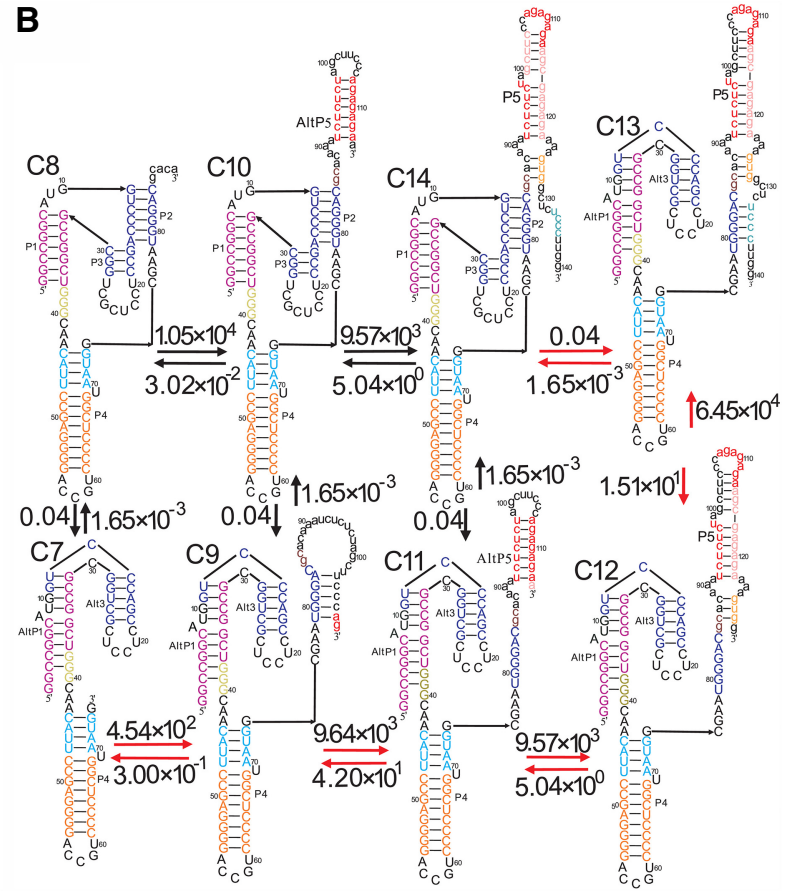

FIGURE 5. (A) The population kinetics of main states (C0-C14) formed during the transcription at a transcription rate of $15 \mathrm{nt} / \mathrm{sec}$ for $\mathrm{HDV}$ ribozyme with 55-nt downstream segment. $(B)$ The folded structures and the transition pathways during the transcription. $\mathrm{C} 0$ to $\mathrm{C} 7$ are the same as in Figure 1.

kinetics theory (Zhao et al. 2010, 2011; Gong et al. 2015a) and the transition node approximation method (Gong et al. 2015b) with pseudoknots (Chen et al. 2014). In this approach, the transition rates for an elementary step are as follows: (i) formation, (ii) disruption of a helix stem, and (iii) helix formation with concomitant partial melting of an incompatible helix, which are calculated with the free energy landscape. Based on the creation/disruption and exchange of helices, we investigated the cotranscription folding behavior of the HDV ribozyme at discrete steps.

The cotranscriptional folding kinetics for the 99-nt HDV ribozyme sequence, two upstream flanking sequences, and one downstream flanking sequence are studied with this new model. Our results indicate that this method is reliable for calculating the cotranscriptional folding kinetics of long mRNA chains. According to our calculations, we found that the cotranscriptional folding kinetics for the 99-nt HDV ribozyme is different from its refolding, which folds into an intermediate trap state, while during transcription, it can effectively avoid the trap intermediates and quickly fold to the cleavage-active state. It is dramatically different from its refolding kinetics. However, the existence of the 30-nt upstream flanking sequence can inhibit the ribozyme region folding into the active native state through forming an alternative helix Alt1 with the segments 70-90. The longer upstream flanking sequence $54 \mathrm{nt}$ itself forms a stable hairpin structure that sequesters the formation of Alt1 helix and leads to rapid formation of cleavage-active structure. Although the 55-nt downstream flanking sequence could invade the already fold- ed active structure during transcription by forming a more stable helix with the ribozyme region, the slow transition rate could keep the structure in the cleavage-active structure to perform the activity.

Our method, based on the transition node approximation, can efficiently reduce the conformation ensemble to study the cotranscriptional folding kinetics of long RNA chains. The transcription rate and transcription pausing, which can be regulated by RNAP, concentration of ribonucleoside triphosphate (rNTP), proteins and other cellar environments, could also be incorporated into our methods. However, the current theory has limitations: The free energy parameters of this model are of RNA at $1 \mathrm{M} \mathrm{NaCl}$ solution condition, and the effect of the $\mathrm{Mg}^{2+}$ ions on these parameters is neglected. But $\mathrm{Mg}^{2+}$ can significantly stabilize the tertiary interactions (Draper 2004; Draper et al. 2005; Grilley et al. 2006; Tan and Chen 2010, 2011) and thus it may possibly alter the folding pathways. Furthermore, we could incorporate the tertiary interaction into this method. First, we obtain all the tertiary structures formed during transcription from the predicted secondary structures; a few methods have been developed to predict the tertiary structures from the secondary structures (Das and Baker 2007; Parisien and Major 2008; Popenda et al. 2012; Zhao et al. 2012; Xu et al. 2014). Then we could get the tertiary interaction through a molecular dynamical simulation (Wang et al. 2016). Hence, this method should be improved to enhance its efficiency as well as incorporate the $\mathrm{Mg}^{2+}$ effects and the effects of other cofactors, such as divalent 
counterion-specific binding and tertiary interaction, into the model.

\section{MATERIALS AND METHODS}

\section{Master equation}

Assuming that there are $\Omega$ states in the RNA conformation space, the population kinetics $P_{i}(t)$ for each state $i$ in the conformation space at time $t$ can be described by the master equation:

$$
\frac{d P_{i}(t)}{d t}=\sum_{j}\left[k_{j \rightarrow i} P_{j}(t)-k_{i \rightarrow j} P_{i}(t)\right]
$$

where $\Sigma_{\mathrm{j}}$ denotes the sum over all the conformations, and $k_{j \rightarrow i}\left(k_{i \rightarrow j}\right)$ is the rate constant for the transition from state $i$ to state $j$ (state $j$ to state $i$ ). The master equation can be written as the following matrix form: $\frac{d \boldsymbol{P}(\boldsymbol{t})}{d t}=\boldsymbol{M} \cdot \boldsymbol{P}(t)$, where $P(t)=\left(P_{1}(t), P_{2}(t), \ldots, P_{\Omega}(t)\right)$ is the fractional population vector, and $\boldsymbol{M}$ is the $\Omega \times \Omega$ rate matrix with elements $M_{i j}=k_{i \rightarrow j}$ for $i=j$ and $M_{i i}=-\sum_{i \neq j} k_{j \rightarrow i}$ for $i \neq j$. Solving the master equation can yield the probability kinetics given the initial folding condition $t>0$ as the following equation:

$$
P(t)=\sum_{m=1} C_{m} n_{m} e^{-\lambda_{m} t},
$$

where $n_{m}$ and $-\lambda_{m}$ are the $m$-th eigenvalue and eigenvector of rate matrix $\boldsymbol{M}$, respectively, and $C_{m}$ is the coefficient that is dependent on the initial condition.

\section{Generating conformation space}

In our model, the rates for formation $\left(k_{+}\right)$and disruption $\left(k_{-}\right)$of a base stack can be calculated as (Zhao et al. 2010) $k_{+}=k_{0} e^{-\Delta G_{+} / k_{B} T}$ and $k_{-}=k_{0} e^{-\Delta G_{-} / k_{B} T}$, respectively, where $k_{0}$ is a prefactor, $k_{B}$ is the Boltzmann constant, $T$ is the temperature, $\Delta G_{+}$and $\Delta G_{-}$are the energy barriers for the formation and disruption of a stack. Recently, it has been validated that the kinetic barrier for the formation of a base stack is concomitant entropic decrease: $\Delta G_{+}=T \Delta S$, and that for the disruption of a base stack is the enthalpic cost: $\Delta G_{-}=\Delta H$, from molecular dynamic simulation (Wang et al. 2016). Thus, the rates for formation and disruption of a base stack (not closing the loop) can be written as follows:

$$
k_{+}=k_{0} e^{-\Delta S_{\text {stack }} / k_{B}}, k_{-}=k_{0} e^{-\Delta H_{\text {stack }} / k_{B} T} .
$$

The rates for formation and disruption of a loop-closing (and the loop) stack are

$$
\begin{aligned}
& k_{+}=k_{0} e^{-\left(\Delta S_{\text {stack }}+\Delta S_{\text {loop }}\right) / k_{B}}, \\
& k_{-}=k_{0} e^{-\Delta H_{\text {stack }} / k_{B} T},
\end{aligned}
$$

where $-\Delta S_{\text {loop }}$ is the entropy change of the loop, $-\Delta S_{\text {stack }}$ and $\Delta H_{\text {stack }}$ are the entropy and enthalpy changes upon formation or disruption of the stack, respectively. The prefactor $k_{0}$ is equal to $6.6 \times$ $10^{12} \mathrm{sec}^{-1}$ for the formation/disruption of a GC base pair and $6.6 \times$ $10^{13} \mathrm{sec}^{-1}$ for an AU base pair (Zhang and Chen 2006; Zhao et al. 2010, 2011; Chen and Zhang 2012; Chen et al. 2014).
The rate for the formation of a base stack is usually larger than that of disrupting the stack, except the loop closing stack under the folding condition; hence, once the first few stacks in a helix are closed and stabilized, zipping of the subsequent stacks in the helix would be fast and it can quickly slip into the fully folded helix (Zhao et al. 2010). This suggests that it is proper to use the helices as building blocks for the study of the overall (i.e., slower) folding kinetics. In our model, the conformation space is constructed upon the helix-based building blocks and the kinetic move is the addition or deletion of a helix or an exchange between two helices (Chen et al. 2014).

In our model (Zhao et al. 2010), RNA structures are constructed by helices, which consist of consecutive base stacks. There are three types of relationships between two helices (Fig. 6):

1. Compatible: The two helices have no overlapping nucleotides with each other (Fig. 6A and B for the secondary structure and the pseudoknot structure, respectively).

2. Partially compatible: The two helices have partial overlapping nucleotides with each other (Fig. 6C and D for the secondary structure and the pseudoknot structure, respectively).

3. Incompatible: The two helices overlapping with each other (Fig. 6E).

Each structure must consist of compatible or partially compatible helices. If helix $H_{m+1}$ is compatible with all the helices $H_{i}(1 \leq i \leq m)$ of the structure containing $m$ helices $\left\{H_{1}, H_{2}, \ldots, H_{i}, \ldots, H_{m}\right\}$, then a new structure with $m+1$ helices $\left\{H_{1}, H_{2}, \ldots, H_{i}, \ldots, H_{m} H_{\mathrm{m}+1}\right\}$ can be formed by adding the new helix $H_{m+1}$ to the $m$-helix structure. However, if helix $H_{m+1}$ is partially compatible with helix $H_{m}$ and compatible with all other helices, adding the helix $H_{m+1}$ would involve an ensemble of $(m+1)$-helix conformations, which contain partially melted helix $H_{m}$ and partially melted helix $H_{m+1}$. Because some base pairs in helix $H_{m}$ would prohibit the formation of certain base pairs in helix $H_{m+1}$, the disruption of such incompatible base pairs in $H_{m}$ would allow the formation of base pairs in $H_{m+1}$.

The free energy of conformations without pseudoknots is calculated by the nearest-neighbor model (Xia et al. 1998; Mathews et al. 1999). The free energy of pseudoknots related conformations is calculated with the model proposed by Chen et al. (2014) based on the model of Eddy (Rivas and Eddy 1999). In the model, the stability of the stacks does not change whether they are involved in a pseudoknot or not, while the free energy of the loop in a pseudoknot is calculated as follows:

$$
\begin{gathered}
G_{p s}=0.83 G_{s s}+0.2 n_{f}+0.1 n_{p}, \text { for } n_{f} \leq 9, \\
G_{p s}=0.83 G_{s s}+0.2\left(9+\log \left(n_{f} / 9\right)\right)+0.1 n_{p}, \text { for } n_{f}>9,
\end{gathered}
$$
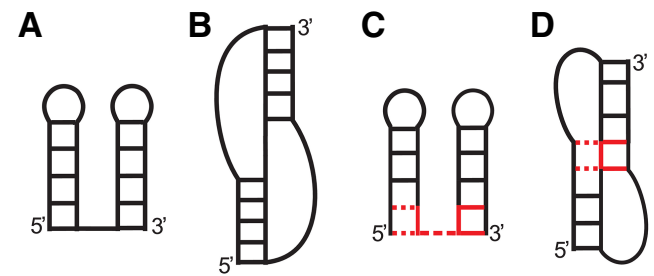

E

FIGURE 6. Relationship of two helices, compatible: $(A)$ and $(B)$, partially compatible: $(C)$ and $(D)$, incompatible: $(E)$. 
where $G_{p s}$ is the free energy of a pseudoknot loop, $G_{s s}$ is the free energy of loops before the pseudoknot is formed, $n_{f}$ is the number of free bases in the pseudoknot, and $n_{p}$ is the number of paired bases in the pseudoknot.

\section{Kinetic move set and rate constant calculation}

\section{Rate of adding or deleting a helix}

As under the folding condition, the zipping pathway is the most probable pathway of forming a helix (Zhao et al. 2010). For the zipping pathway (Fig. 7A), as the rate for forming the first loop-closing stack is much smaller than that for adding a new stack to the existing stack, so the formation of the first stack is the rate-limited for formation of the helix. Hence, the free energy landscape shows a downhill profile after the formation of the third base stack. The rate $k_{f}$ of the helix formation (along one specific pathway) could be approximated as the rate for the formation of the three-stack state (Zhao et al. 2010):

$$
\begin{aligned}
k_{f} & =k_{1 \rightarrow 2} K_{1}\left(1-K_{2}^{\prime} K_{1}^{\prime} \sum_{n=0}^{\infty}\left(K_{2}^{\prime} K_{1}\right)^{n}\right) \\
& =k_{1 \rightarrow 2} K_{1}\left(1-K_{2}^{\prime} K_{1}^{\prime} \frac{1}{1-K_{2}^{\prime} K_{1}}\right),
\end{aligned}
$$

where $k_{i \rightarrow j}$ denotes the transition rate from state $i$ to $j, K_{i}$ and $K_{i}^{\prime}$ are the forward and reverse probability of state $i$ :

$$
\begin{aligned}
& K_{1}=\frac{k_{2 \rightarrow 3}}{k_{2 \rightarrow 3}+k_{2 \rightarrow 1}}, K_{1}^{\prime}=\frac{k_{2 \rightarrow 1}}{k_{2 \rightarrow 3}+k_{2 \rightarrow 1}}, \\
& K_{2}=\frac{k_{3 \rightarrow 4}}{k_{3 \rightarrow 4}+k_{3 \rightarrow 2}}, K_{2}^{\prime}=\frac{k_{3 \rightarrow 2}}{k_{3 \rightarrow 4}+k_{3 \rightarrow 2}} .
\end{aligned}
$$

After the first base stack could be formed anywhere inside the helix for a given RNA molecular, the rate $k_{F}$ for formation of a helix is the sum of the rates along all the pathways (Fig. 7B) with the different first (nucleation) base stacks. The rate for deleting the helix can be estimated from the detailed balance condition:

$$
k_{U}=k_{F} e^{-\Delta G / k_{B} T},
$$

where $\Delta G$ is the free energy difference between the two structures.

\section{Rate of exchanging between two helices}

If two helices are incompatible, they cannot coexist in the same structure. The most probable pathway of the conversion from helix $A$ to helix $B$ is the tunneling pathway (Fig. 8), where after the first two base stacks of helix A are disrupted, in each subsequent step, disruption of a stack in helix $A$ is accompanied by formation of a stack in helix $B$. Based on the tunneling pathway, the rate for helix exchange can be calculated as (Zhao et al. 2010):

$$
\begin{aligned}
k_{A \rightarrow B} & =\frac{\prod_{i}^{n} k_{i \rightarrow i+1}}{\sum_{j=0}^{n-1}\left(\prod_{i=1}^{j} k_{i+1 \rightarrow i} \prod_{m=j+2}^{n} k_{m \rightarrow m+1}\right)}, k_{B \rightarrow A} \\
& =k_{A \rightarrow B} e^{-\Delta G_{A B} / k_{B} T}
\end{aligned}
$$

where $k_{i \rightarrow i+1}$ is the rate constant for the formation (disruption) of a base stack in $A(B)$, and $k_{i+1 \rightarrow i}$ is the rate constant for the disruption (formation) of a base stack in $A(B) . \Delta G_{A B}$ is the free energy difference between structure $A$ and structure $B$.

\section{Cotranscriptional folding kinetics}

In our model (Zhao et al. 2011), releasing one nucleotide by RNA polymerase (RNAP) to freely form possible structures can be regarded as a transcriptional step. If the transcription speed of a RNA sequence is $v$ nucleotides per seconds, the (real) time window for $M$-th nucleotide (nt) to be (newly) transcribed to the $(M+1)$-th nucleotide will be $1 / v$ sec. Then the $M$-nt chain samples, the conformation space $\Omega$ in the $1 / v$ sec and its population distribution is relaxed from $\left[p_{1}(M)_{\text {begin }}, p_{2}(M)_{\text {begin }}, \ldots, p_{\Omega}(M)_{\text {begin }}\right]$ to $\left[p_{1}(M)_{\text {end }}\right.$, $\left.p_{2}(M)_{\text {end }}, \ldots, p_{\Omega}(M)_{\text {end }}\right]$, where the $p_{i}(M)_{\text {begin }}, p_{i}(M)_{\text {end }}$ are the populations of state $i$ at the beginning and the end of the step $M$, respectively. This is defined as the $M-n t$ step. For each step, the population kinetics is calculated in the same manner.

The beginning population of the $M$-th step can be inherited from the ending population of the $(M-1)$-th step. According to the possible changes of the structures upon the extension of the chain by one nucleotide, the structures in the current step can by classified as four types (Fig. 9). Types a and b: The newly transcribed $M$-th nucleotide does not pair with any nucleotides. The new $M$-th nt chain can retain the same structure as the $(M-1)$-th nt chain. Type c: The newly transcribed nucleotide can pair with an upstream nucleotide to elongate a helix by one base pair. Because the zipping of a new stack (base pair) is much faster than transcribing a nucleotide (Zhao et al. 2011), the two structures can be recognized as "directly inherited" and thus have the same population. Type d: the newly
FIGURE 7. (A) The free energy landscape along the zipping pathway. (B) Multiple pathways for the formation of a helix, the red solid lines denote the newly formed base pairs. 


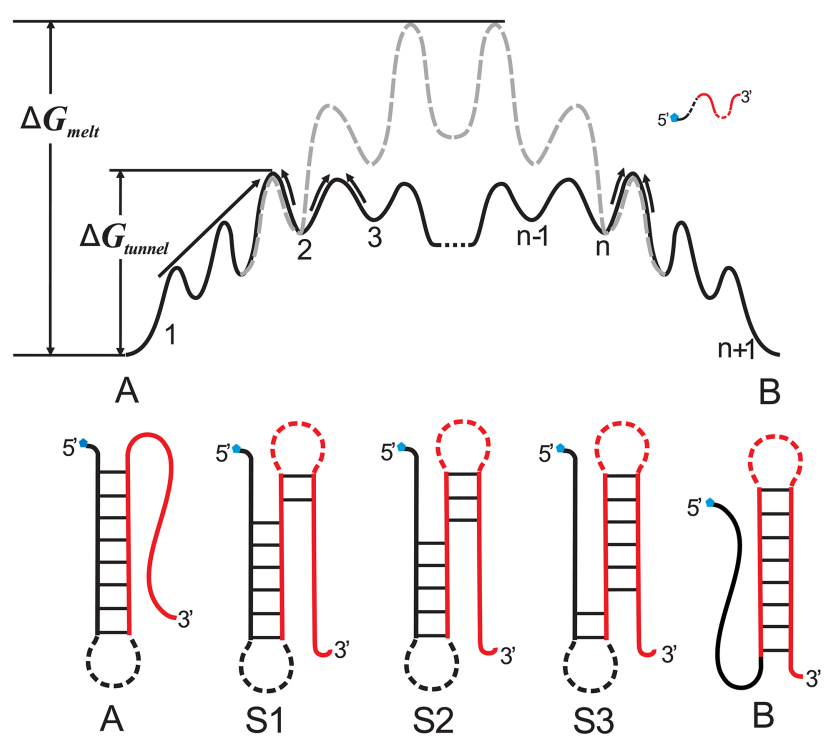

FIGURE 8. The free energy landscape for the transition between helices $A$ and $B$. (Solid line) The tunneling pathway. (Dotted line) Completely unfolding helix $A$ followed by refolding to $B$. The $5^{\prime}$ end of the RNA chain is denoted by a blue pentagram.

transcribed nucleotide can pair with another nucleotide to form a new helix, which cannot be formed in the previous step. In this category, all structures in the current step containing the new helix have a population of zero at the beginning of the $M$-th step. Then the population distribution at the beginning of step $M$ can be summarized by

$$
\begin{array}{cl}
p(M)_{\text {begin }}=p(M-1)_{\text {end }} & \text { for } a, b \text {, and } c ; \\
p(M)_{\text {begin }}=0 & \text { for } d .
\end{array}
$$

The folding kinetics for the RNA chain during the transcription can be computed by applying this method from the first step to the end of transcription.

\section{Transition node approximation}

All the possible structures of the $M$-th step can be divided into two ensembles (Fig. 9): $\Omega_{\text {old }}$, in which the states are of the a, b, and c types and with nonzero initial population; and $\Omega_{\text {new }}$, in which the states (type d) contain the newly formed helix at this step and with zero initial population. Most of the initial population at each transcriptional step is mainly concentrated in a few stable and metastable states (Zhao et al. 2010), which comprise the subensemble $\Omega_{\text {old }}^{h}$. The threshold for the initial population of states in $\Omega_{\text {old }}^{h}$ is set to be 0.03 , which can ensure that above $90 \%$ of the population is occupied by states in $\Omega_{\text {old }}^{h}$ at each transcription step for HDV. If the new states are much more unstable than these old states in $\Omega_{\text {old }}^{h}$, it is impossible for them to obtain a pop- ulation. Assuming that the free energy of the most unstable states in $\Omega_{\text {old }}^{h}$ is maxE, then the new conformation ensemble $\Omega_{\text {new }}$ can be divided into two sub-ensembles: $\Omega_{\text {new }}^{h}$, in which all the free energy of each conformation is lower than $(\max E+2) \mathrm{kcal} / \mathrm{mol}$; and $\Omega_{n e w}^{r}$, which contains the rest conformations in $\Omega_{n e w}$. As the free energy of these structures in $\Omega_{\text {new }}^{r}$ is at least $+2 \mathrm{kcal} / \mathrm{mol}$ higher than those in $\Omega_{\text {old }}^{h}$, so they can occupy far less than $1 \%$ of the population even at equilibrium. Thus, for the newly formed conformations, only those in $\Omega_{\text {new }}^{h}$ are possible to have the population accumulation. Although states in $\Omega_{\text {new }}^{r}$ are unlikely to contribute to the population aggregation, some conformations may be on the main pathways for population flow. So the reduced assemble conformation space consists of structures in $\Omega_{\text {old }}, \Omega_{\text {new }}^{h}$, and parts of $\Omega_{\text {new }}^{r}$.

Because the transcriptional time scale of HDV is smaller than 15 $\mathrm{sec}$, if the rate of one transition pathway is much less than (0.0044) $\mathrm{sec}^{-1}$, there almost will be no RNAs folded via this pathway. Hence, if the transition rates along the direction of the population flow slower than (0.0044) $\mathrm{sec}^{-1}$, they are unlikely to contribute to the folding. Thus, we only consider the pathways through states in $\Omega_{\text {old }}^{h}$ that can transit to states in $\Omega_{\text {new }}^{h}$ with corresponding transition rates greater than (0.0044) $\mathrm{sec}^{-1}$, and if there is no pathway between the two states, then we will relax the criteria to nine nodes or more to avoid isolate states in the transition network. After all the possible transitions are searched, the structures in $\Omega_{\text {old }}, \Omega_{\text {new }}^{h}$, together with the structures in $\Omega_{\text {new }}^{r}$ located in the saved transition

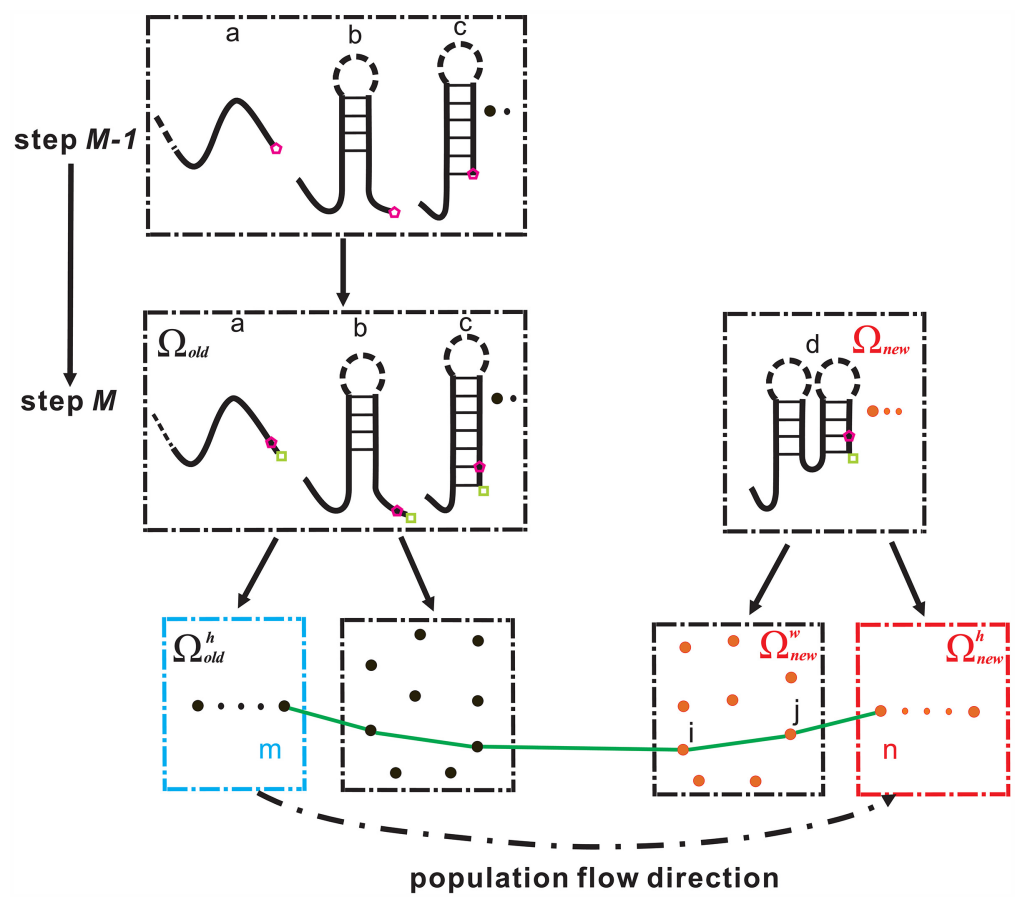

FIGURE 9. The population lineage and the transition node approximation at the $M$-th step. The pentagram and square denote the last nucleotide released by RNAP at steps $M-1$ and $M$, respectively. The conformation space at the $M$-th step can be divided into two ensembles: $\Omega_{\text {old }}$, the conformation ensemble of states directly inherited from step $M-1$; and $\Omega_{\text {new }}$, the conformation ensemble of states newly formed at step $M$ and with zero initial population. $\Omega_{\text {old }}^{h}$ : a sub-ensemble of $\Omega_{\text {old }}$, in which the initial population of each state is larger than $0.03 . \Omega_{\text {new }}^{h}$ : a sub-ensemble of $\Omega_{\text {new }}$, in which each state has the free energy $\Delta G \leq(\max E+2) \mathrm{kcal} / \mathrm{mol}$, where $\max E$ is the free energy of the most unstable state in $\Omega_{\text {old }}^{h}$. $\Omega_{\text {new }}^{w}$ : an ensemble of all rest states of $\Omega_{\text {new }}$. The green line shows the assumed transition pathway between state $\mathrm{m}$ and state $\mathrm{n}$, whereas the two intermediate states are denoted by $i$ and $j$. 
pathways build up the conformation ensemble used for subsequent calculations.

\section{ACKNOWLEDGMENTS}

This work was partially supported by the National Natural Science Foundation of China under grant numbers 11574234 and 31270761 (to W.Z.) and grant number 31600592 (to S.G.).

Received February 6, 2018; accepted June 25, 2018.

\section{REFERENCES}

Ameur A, Zaghlool A, Halvardson J, Wetterbom A, Gyllensten U, Cavelier L, Feuk L. 2011. Total RNA sequencing reveals nascent transcription and widespread co-transcriptional splicing in the human brain. Nat Struct Mol Biol 18: 1435-1440.

Artsimovitch I, Landick R. 2000. Pausing by bacterial RNA polymerase is mediated by mechanistically distinct classes of signals. Proc Natl Acad Sci 97: 7090-7095.

Batey RT, Gilbert SD, Montange RK. 2004. Structure of a natural guanine-responsive riboswitch complexed with the metabolite hypoxanthine. Nature 432: 411-415.

Brehm SL, Cech TR. 1983. The fate of an intervening sequence RNA: excision and cyclization of the Tetrahymena ribosomal RNA intervening sequence in vivo. Biochemistry 22: 2390-2397.

Brugiolo M, Herzel L, Neugebauer KM. 2013. Counting on co-transcriptional splicing. F1000prime Rep 5: 9.

Cao S, Chen S. 2005. Predicting RNA folding thermodynamics with a reduced chain representation model. RNA 11: 1884-1897.

Cao S, Chen SJ. 2006. Predicting RNA pseudoknot folding thermodynamics. Nucleic Acids Res 34: 2634-2652.

Chadalavada DM, Knudsen SM, Nakano S, Bevilacqua PC. 2000. A role for upstream RNA structure in facilitating the catalytic fold of the genomic hepatitis delta virus ribozyme. J Mol Biol 301: 349-367.

Chadalavada DM, Senchak SE, Bevilacqua PC. 2002. The folding pathway of the genomic hepatitis delta virus ribozyme is dominated by slow folding of the pseudoknots. J Mol Biol 317: 559-575.

Chadalavada DM, Cerrone-Szakal AL, Bevilacqua PC. 2007. Wild-type is the optimal sequence of the HDV ribozyme under cotranscriptional conditions. RNA 13: 2189-2201.

Cheah MT, Wachter A, Sudarsan N, Breaker RR. 2007. Control of alternative RNA splicing and gene expression by eukaryotic riboswitches. Nature 447: 497-500.

Chen J, Greider CW. 2005. Functional analysis of the pseudoknot structure in human telomerase RNA. Proc Natl Acad Sci 102: 8080-8085.

Chen J, Zhang W. 2012. Kinetic analysis of the effects of target structure on siRNA efficiency. J Chem Phys 137: 225102.

Chen J, Gong S, Wang Y, Zhang W. 2014. Kinetic partitioning mechanism of HDV ribozyme folding. J Chem Phys 140: 25102.

Cho SS, Pincus DL, Thirumalai D. 2009. Assembly mechanisms of RNA pseudoknots are determined by the stabilities of constituent secondary structures. Proc Natl Acad Sci 106: 17349-17354.

Comolli LR, Smirnov I, Xu L, Blackburn EH, James TL. 2002. A molecular switch underlies a human telomerase disease. Proc Natl Acad Sci 99: 16998-17003.

Cornish PV, Hennig M, Giedroc DP. 2005. A loop 2 cytidine-stem 1 minor groove interaction as a positive determinant for pseudoknot-stimulated -1 ribosomal frameshifting. Proc Natl Acad Sci 102: 12694-12699.

Danilova LV, Pervouchine DD, Favorov AV, Mironov AA. 2006. RNAKinetics: a web server that models secondary structure kinetics of an elongating RNA. J Bioinform Comput Biol 4: 589-596.

Das R, Baker D. 2007. Automated de novo prediction of native-like RNA tertiary structures. Proc Natl Acad Sci 104: 14664-14669.

Denesyuk NA, Thirumalai D. 2011. Crowding promotes the switch from hairpin to pseudoknot conformation in human telomerase RNA. J Am Chem Soc 133: 11858-11861.
Diegelman-Parente A, Bevilacqua PC. 2002. A mechanistic framework for co-transcriptional folding of the HDV genomic ribozyme in the presence of downstream sequence. J Mol Biol 324: 1-16.

Draper DE. 2004. A guide to ions and RNA structure. RNA 10: 335-343.

Draper DE, Grilley D, Soto AM. 2005. Ions and RNA folding. Annu Rev Biophys Biomol Struct 34: 221-243.

Ferré-D’Amaré AR, Zhou K, Doudna JA. 1998. Crystal structure of a hepatitis delta virus ribozyme. Nature 395: 567-574.

Flamm C, Fontana W, Hofacker IL, Schuster P. 2000. RNA folding at elementary step resolution. RNA 6: 325-338.

Geis M, Flamm C, Wolfinger MT, Tanzer A, Hofacker IL, Middendorf M, Mandl C, Stadler PF, Thurner C. 2008. Folding kinetics of large RNAs. J Mol Biol 379: 160-173.

Gesteland RF, Atkins JF. 1996. Recoding: dynamic reprogramming of translation. Annu Rev Biochem 65: 741-768.

Giedroc DP, Theimer CA, Nixon PL. 2000. Structure, stability and function of RNA pseudoknots involved in stimulating ribosomal frameshifting. J Mol Biol 298: 167-185.

Gong S, Wang Y, Zhang W. 2015a. Kinetic regulation mechanism of pbuE riboswitch. J Chem Phys 142: 15103.

Gong S, Wang Y, Zhang W. 2015b. The regulation mechanism of yitJ and metF riboswitches. J Chem Phys 143: 45103.

Grilley D, Soto AM, Draper DE. 2006. $\mathrm{Mg}^{2+}$-RNA interaction free energies and their relationship to the folding of RNA tertiary structures. Proc Natl Acad Sci 103: 14003-14008.

Grundy FJ, Henkin TM. 1998. The S box regulon: a new global transcription termination control system for methionine and cysteine biosynthesis genes in Gram-positive bacteria. Mol Microbiol 30: 737-749.

Gultyaev AP. 1991. The computer simulation of RNA folding involving pseudoknot formation. Nucleic Acids Res 19: 2489-2494.

Gusarov I, Nudler E. 1999. The mechanism of intrinsic transcription termination. Mol Cell 3: 495.

Hamperl S, Cimprich KA. 2014. The contribution of co-transcriptional RNA: DNA hybrid structures to DNA damage and genome instability. DNA Repair 19: 84-94.

Heilman-Miller SL, Woodson SA. 2003. Effect of transcription on folding of the Tetrahymena ribozyme. RNA 9: 722-733.

Helmling C, Klötzner DP, Sochor F, Mooney RA, Wacker A, Landick R, Fürtig B, Heckel A, Schwalbe H. 2018. Life times of metastable states guide regulatory signaling in transcriptional riboswitches. Nat Commun 9: 944.

Hofacker IL, Flamm C, Heine C, Wolfinger MT, Scheuermann G, Stadler PF. 2010. BarMap: RNA folding on dynamic energy landscapes. RNA 16: 1308-1316.

Hoffmann S, Otto C, Doose G, Tanzer A, Langenberger D, Christ S, Kunz M, Holdt LM, Teupser D, Hackermüller J, et al. 2014. A multi-split mapping algorithm for circular RNA, splicing, trans-splicing and fusion detection. Genome Biol 15: R34.

Isambert H, Siggia ED. 2000. Modeling RNA folding paths with pseudoknots: application to hepatitis delta virus ribozyme. Proc Natl Acad Sci 97: 6515-6520.

Kapral GJ, Jain S, Noeske J, Doudna JA, Richardson DC, Richardson JS. 2014. New tools provide a second look at HDV ribozyme structure, dynamics and cleavage. Nucleic Acids Res 42: 12833-12846.

Karayiannis P. 1998. Hepatitis D virus. Rev Med Virol 8: 13-24.

Kim Y, Su L, Maas S, O’Neill A, Rich A. 1999. Specific mutations in a viral RNA pseudoknot drastically change ribosomal frameshifting efficiency. Proc Natl Acad Sci 96: 14234-14239.

Kramer FR, Mills DR. 1981. Secondary structure formation during RNA synthesis. Nucleic Acids Res 9: 5109-5124.

Krasovska MV, Sefcikova J, Špačková N, Šponer J, Walter NG. 2005. Structural dynamics of precursor and product of the RNA enzyme from the hepatitis delta virus as revealed by molecular dynamics simulations. J Mol Biol 351: 731-748.

Lai MM. 1995. The molecular biology of hepatitis delta virus. Annu Rev Biochem 64: 259-286.

Lazinski DW, Taylor JM. 1995. Regulation of the hepatitis delta virus ribozymes: to cleave or not to cleave? RNA 1: 225. 
Lehnert V, Jaeger L, Michele F, Westhof E. 1996. New loop-loop tertiary interactions in self-splicing introns of subgroup IC and ID: a complete 3D model of the Tetrahymena thermophila ribozyme. Chem Biol 3: 993-1009.

Li S, Breaker RR. 2013. Eukaryotic TPP riboswitch regulation of alternative splicing involving long-distance base pairing. Nucleic Acids Res 41: 3022-3031.

Lin J, Thirumalai D. 2008. Relative stability of helices determines the folding landscape of adenine riboswitch aptamers. J Am Chem Soc 130: $14080-14081$.

Lin J, Thirumalai D. 2013. Kinetics of allosteric transitions in S-adenosylmethionine riboswitch are accurately predicted from the folding landscape. J Am Chem Soc 135: 16641-16650.

Marrone A, Walne A, Dokal I. 2005. Dyskeratosis congenita: telomerase, telomeres and anticipation. Curr Opin Genet Dev 15: 249-257.

Mathews DH, Sabina J, Zuker M, Turner DH. 1999. Expanded sequence dependence of thermodynamic parameters improves prediction of RNA secondary structure. J Mol Biol 288: 911-940.

Mercer TR, Dinger ME, Mattick JS. 2009. Long non-coding RNAs: insights into functions. Nat Rev Genet 10: 155-159.

Mironov AA, Dyakonova LP, Kister AE. 1985. A kinetic approach to the prediction of RNA secondary structures. J Biomol Struct Dyn 2: 953-962.

Neupane K, Yu H, Foster DA, Wang F, Woodside MT. 2011. Singlemolecule force spectroscopy of the add adenine riboswitch relates folding to regulatory mechanism. Nucleic Acids Res 39: 7677-7687.

Pan J, Woodson SA. 1999. The effect of long-range loop-loop interactions on folding of the Tetrahymena self-splicing RNA. J Mol Biol 294: 955-965.

Parisien M, Major F. 2008. The MC-Fold and MC-Sym pipeline infers RNA structure from sequence data. Nature 452: 51.

Perrotta AT, Been MD. 1990. The self-cleaving domain from the genomic RNA of hepatitis delta virus: sequence requirements and the effects of denaturant. Nucleic Acids Res 18: 6821-6827.

Perrotta AT, Been MD. 1991. A pseudoknot-like structure required for efficient self-cleavage of hepatitis delta virus RNA. Nature 350: 434-436.

Plant EP, Dinman JD. 2005. Torsional restraint: a new twist on frameshifting pseudoknots. Nucleic Acids Res 33: 1825-1833.

Plant EP, Jacobs KL, Harger JW, Meskauskas A, Jacobs JL, Baxter JL, Petrov AN, Dinman JD. 2003. The 9-Å solution: how mRNA pseudoknots promote efficient programmed -1 ribosomal frameshifting. RNA 9: 168-174.

Popenda M, Szachniuk M, Antczak M, Purzycka KJ, Lukasiak P, Bartol N, Blazewicz J, Adamiak RW. 2012. Automated 3D structure composition for large RNAs. Nucleic Acids Res 40: e112.

Reining A, Nozinovic S, Schlepckow K, Buhr F, Fürtig B, Schwalbe H. 2013. Three-state mechanism couples ligand and temperature sensing in riboswitches. Nature 499: 355-359.

Rivas E, Eddy SR. 1999. A dynamic programming algorithm for RNA structure prediction including pseudoknots. $J \mathrm{Mol}$ Biol 285: 2053-2068.

Russell R, Millett IS, Doniach S, Herschlag D. 2000. Small angle X-ray scattering reveals a compact intermediate in RNA folding. Nat Struct Mol Biol 7: 367-370.

Schultes EA, Bartel DP. 2000. One sequence, two ribozymes: implications for the emergence of new ribozyme folds. Science 289: 448-452.

Sharma CM, Hoffmann S, Darfeuille F, Reignier J, Findeiss S, Sittka A, Chabas S, Reiche K, Hackermüller J, Reinhardt R. 2010. The primary transcriptome of the major human pathogen Helicobacter pylori. Nature 464: 250-255.

Shi B, Cho SS, Thirumalai D. 2011. Folding of human telomerase RNA pseudoknot using ion-jump and temperature-quench simulations. J Am Chem Soc 133: 20634-20643.

Skog J, Würdinger T, Van Rijn S, Meijer DH, Gainche L, Curry WT, Carter BS, Krichevsky AM, Breakefield XO. 2008. Glioblastoma microvesicles transport RNA and proteins that promote tumour growth and provide diagnostic biomarkers. Nat Cell Biol 10: 1470-1476.
Sorin EJ, Engelhardt MA, Herschlag D, Pande VS. 2002. RNA simulations: probing hairpin unfolding and the dynamics of a GNRA tetraloop. J Mol Biol 317: 493-506.

Tan Z, Chen S. 2010. Predicting ion binding properties for RNA tertiary structures. Biophys J 99: 1565-1576.

Tan Z, Chen S. 2011. Salt contribution to RNA tertiary structure folding stability. Biophys J 101: 176-187.

Tang X, Thomas S, Tapia L, Giedroc DP, Amato NM. 2008. Simulating RNA folding kinetics on approximated energy landscapes. J Mol Biol 381: 1055-1067.

Taylor JM. 2006. Structure and replication of hepatitis delta virus RNA. Curr Top Microbiol Immunol 307: 1-23.

Taylor DR, Lee SB, Romano PR, Marshak DR, Hinnebusch AG, Esteban M, Mathews MB. 1996. Autophosphorylation sites participate in the activation of the double-stranded-RNA-activated protein kinase PKR. Mol Cell Biol 16: 6295-6302.

Theimer CA, Finger LD, Trantirek L, Feigon J. 2003. Mutations linked to dyskeratosis congenita cause changes in the structural equilibrium in telomerase RNA. Proc Natl Acad Sci 100: 449-454.

Tilgner H, Knowles DG, Johnson R, Davis CA, Chakrabortty S, Djebali S, Curado J, Snyder M, Gingeras TR, Guigó R. 2012. Deep sequencing of subcellular RNA fractions shows splicing to be predominantly co-transcriptional in the human genome but inefficient for lncRNAs. Genome Res 22: 1616-1625.

Treiber DK, Williamson JR. 1999. Exposing the kinetic traps in RNA folding. Curr Opin Struct Biol 9: 339-345.

Treiber DK, Williamson JR. 2001. Beyond kinetic traps in RNA folding. Curr Opin Struct Biol 11: 309-314.

Treiber DK, Rook MS, Zarrinkar PP, Williamson JR. 1998. Kinetic intermediates trapped by native interactions in RNA folding. Science 279: 1943-1946.

Veeraraghavan N, Bevilacqua PC, Hammes-Schiffer S. 2010. Long-distance communication in the HDV ribozyme: insights from molecular dynamics and experiments. J Mol Biol 402: 278-291.

Wadkins TS, Perrotta AT, Ferré-D'amaré AR, Doudna JA, Been MD. 1999. A nested double pseudoknot is required for self-cleavage activity of both the genomic and antigenomic hepatitis delta virus ribozymes. RNA 5: 720-727.

Wang Y, Gong S, Wang Z, Zhang W. 2016. The thermodynamics and kinetics of a nucleotide base pair. J Chem Phys 144: 115101.

Wong TN, Sosnick TR, Pan T. 2007. Folding of noncoding RNAs during transcription facilitated by pausing-induced nonnative structures. Proc Natl Acad Sci 104: 17995-18000.

Wu M, Tinoco I. 1998. RNA folding causes secondary structure rearrangement. Proc Natl Acad Sci 95: 11555-11560.

Xia T, SantaLucia JJr., Burkard ME, Kierzek R, Schroeder SJ, Jiao X, Cox C, Turner DH. 1998. Thermodynamic parameters for an expanded nearest-neighbor model for formation of RNA duplexes with Watson-Crick base pairs. Biochemistry 37: 14719-14735.

Xu X, Zhao P, Chen SJ. 2014. Vfold: a web server for RNA structure and folding thermodynamics prediction. PLos One 9: e107504.

Yingling YG, Shapiro BA. 2005. Dynamic behavior of the telomerase RNA hairpin structure and its relationship to dyskeratosis congenita. J Mol Biol 348: 27-42.

Zarrinkar PP, Williamson JR. 1996. The kinetic folding pathway of the Tetrahymena ribozyme reveals possible similarities between RNA and protein folding. Nat Struct Mol Biol 3: 432-438.

Zhang W, Chen S. 2006. Exploring the complex folding kinetics of RNA hairpins: I. General folding kinetics analysis. Biophys J 90: 765-777.

Zhang J, Lin M, Chen R, Wang W, Liang J. 2008. Discrete state model and accurate estimation of loop entropy of RNA secondary structures. J Chem Phys 128: 125107.

Zhao P, Zhang W, Chen S. 2010. Predicting secondary structural folding kinetics for nucleic acids. Biophys J 98: 1617-1625.

Zhao P, Zhang W, Chen S. 2011. Cotranscriptional folding kinetics of ribonucleic acid secondary structures. J Chem Phys 135: 245101.

Zhao Y, Huang Y, Zhou G, Wang Y, Man J, Xiao Y. 2012. Automated and fast building of three-dimensional RNA structures. Sci Rep 2: 734. 

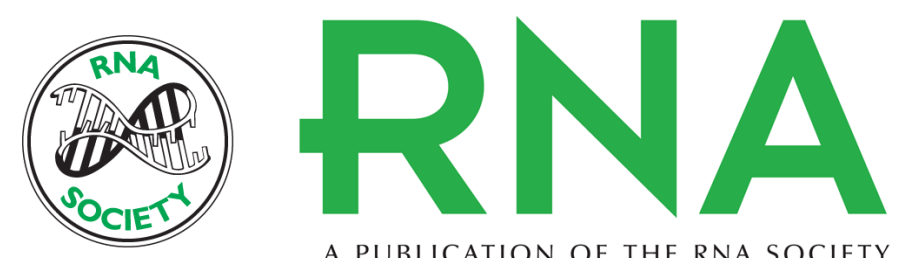

A PUBLICATION OF THE RNA SOCIETY

\section{Effects of flanking regions on HDV cotranscriptional folding kinetics}

Yanli Wang, Zhen Wang, Taigang Liu, et al.

RNA 2018 24: 1229-1240 originally published online June 28, 2018

Access the most recent version at doi:10.1261/rna.065961.118

References This article cites 95 articles, 24 of which can be accessed free at: http://rnajournal.cshlp.org/content/24/9/1229.full.html\#ref-list-1

Creative This article is distributed exclusively by the RNA Society for the first 12 months after the Commons full-issue publication date (see http://rnajournal.cshlp.org/site/misc/terms.xhtml). After 12 License months, it is available under a Creative Commons License (Attribution-NonCommercial 4.0 International), as described at http://creativecommons.org/licenses/by-nc/4.0/.

Email Alerting Receive free email alerts when new articles cite this article - sign up in the box at the Service top right corner of the article or click here.

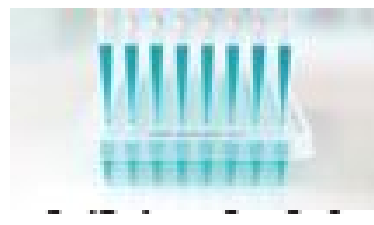

Providing Precise Solutions for your research.

To subscribe to $R N A$ go to:

http://rnajournal.cshlp.org/subscriptions

(C) 2018 Wang et al.; Published by Cold Spring Harbor Laboratory Press for the RNA Society 